\title{
CELLULAR AUTOMATA (CA) CONTIGUITY FILTERS IMPACTS ON CA MARKOV MODELING OF LAND USE LAND COVER CHANGE PREDICTIONS RESULTS
}

\author{
Md. Surabuddin Mondal ${ }^{1 *}$, Nayan Sharma², Martin Kappas³, P. K. Garg ${ }^{4}$ \\ ${ }^{1}$ Dept. of Surveying Engineering, Wollega University, Ethiopia - msk.iit@ gmail.com \\ ${ }^{2}$ Center for Transportation System (CTRANS), Indian Institute of Technology, Roorkee, India - nayanfwt@ gmail.com \\ ${ }^{3}$ Dept. of Cartography, GIS \& Remote Sensing, Institute of Geography, Georg-August University of Göttingen, Goldschmidtstr. 5, \\ Room No. 477, 37077, Göttingen, Germany - mkappas@gwdg.de \\ ${ }^{4}$ Dept. of (Geomatics) Engineering, Indian Institute of Technology, Roorkee, India - pkgiitr@ gmail.com
}

\begin{abstract}
KEY WORDS: CA Markov Modeling, LULCC Prediction, Validation, Cellular Automata (CA) Contiguity Filters, Effects on Prediction Results.
\end{abstract}

\begin{abstract}
:
In this study, attempts has been made to find out cellular automata (CA) contiguity filters impacts on Land use land cover change predictions results. Cellular Automata (CA) Markov chain model used to monitor and predict the future land use land cover pattern scenario in a part of Brahmaputra River Basin, India, using land use land cover map derived from multi-temporal satellite images. Land use land cover maps derived from satellite images of Landsat MSS image of 1987 and Landsat TM image of 1997 were used to predict future land use land cover of 2007 using Cellular Automata Markov model. The validity of the Cellular Automata Markov process for projecting future land use and cover changes calculates using various Kappa Indices of Agreement (Kstandard) predicted (results) maps with the reference map (land use land cover map derived from IRS-P6 LISS III image of 2007). The validation shows Kstandard is $0.7928 .3 \times 3,5 \times 5$ and $7 \times 7$ CA contiguity filters are evaluated to predict LULC in 2007 using 1987 and 1997 LULC maps. Regression analysis have been carried out for both predicted quantity as well as prediction location to established the cellular automata (CA) contiguity filters impacts on predictions results. Correlation established that predicted LULC of 2007 and LULC derived from LISS III Image of 2007 are strongly correlated and they are slightly different to each-other but the quantitative prediction results are same for when $3 \times 3,5 \times 5$ and $7 \times 7$ CA contiguity filters are evaluated to predict land use land cover. When we look at the quantity of predicted land use land cover of 2007 area statistics are derived by using $3 \times 3,5 \times 5$ and $7 \times 7$ CA contiguity filters, the predicted area statistics are the same. Other hands, the spatial difference between predicted LULC of 2007 and LULC derived from LISS III images of 2007 is evaluated and they are found to be slightly different. Correlation coefficient (r) between predicted LULC classes and LULC derived from LISS III image of 2007 using 3x3, 5x5, 7x7 are 0.7906, 0.7929, 0.7927, respectively. Therefore, the correlation coefficient (r) for $5 \times 5$ contiguity filters is highest among $3 \times 3,5 \times 5$, and $7 \times 7$ filters and established/produced most geographically / spatially distributed effective results, although the differences between them are very small.
\end{abstract}

\section{INTRODUCTION}

CA Markov model combines both the concept of a CA filter and Markov chain procedure. Markov chain and CA both is the discrete dynamic model in time and state. The transition probabilities may be accurate on per category basis, but there is no knowledge of the spatial distribution of occurrences within each LULC category. CA will add spatial character to the model. CA is a discrete dynamic system in which the state of each cell at time $t+1$ is determined by the stated of its neighboring cells at time according the pre-defined transition rules. CA as a method with temporal-spatial dynamics can simulate the evolution of things in two dimensions. Using the outputs from the Markov chain analysis, the transition matrix, CA Markov will apply a contiguity filter to 'grow out' LULC from the time two to a later time periods. CA Markov will use the transition areas tables and the conditional probability images to predict land use and land cover changes over the periods specified in Markov chain analysis. Although, the transition probabilities are accurate on a per category basis, there is no knowledge of the spatial distribution of the occurrences within each category i.e., there is no spatial components in the outcome. In essence, the CA will develop a spatially explicit weighting factor which will be applied to each of the suitability, weighting more heavily areas that proximate to existing LULC. This will ensure that land use and land cover change occur proximate to existing, like LULC classes and not wholly random. CA Markov will produce much better results geographically using the contiguity filter; those areas likely to change will do so proximity to existing LULC classes. The Markov model alone lacks knowledge of spatial dependence. CA Markov gives more spatially dependence results. CA can add spatial characteristics to the model. In other words, the main problem of Markov analysis is that it is insensitive to space and it provides no sense of geography. Although the transition probabilities may be accurate for a particular class as a whole, there is no spatial element to the modeling process. CA adds a spatial dimension to the model.

$\mathrm{CA}$ adds a spatial dimension to the model.

\footnotetext{
* Corresponding author
} 


\subsection{CELLULAR AUTOMATA (CA) MARKOV MODEL}

CA was firstly used by Von Neumann (1966) for selfreproducible systems. In CA, Von Neumann neighborhood comprises of four cells orthogonally surrounding a central cell on a two-dimensional square lattice (Figure 1a). The neighborhood is named after John von Neumann. It is one of the two most commonly used neighborhood types, the other one being the 8-cell Moore neighborhood. It is similar to the notion of 4-connected pixels in computer graphics (Figure 1b).

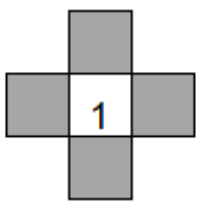

(a)

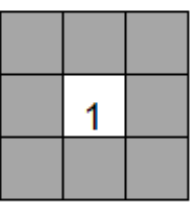

(b)
Figure 1.a. The Von Neumann neighbor of cell '1'; Figure 1b: The Moore neighbor of cell ' 1 '

A CA filter is used to generate a spatial explicit contiguityweighting factor to change the state of cells based on its neighbors. The filter is integral to the action of the CA component. Its purpose is to down-weight the suitability's of pixels that are distant from existing instances of the land cover type under consideration. The net effect is that to be a likely choice for land cover conversion, the pixel must be both inherently suitable and near to existing areas of that class. The $3 \times 3,5 \times 5$ and $7 \times 7$ contiguity filters have the following kernel:

3X3
\begin{tabular}{|l|l|l|}
\hline 0 & 1 & 0 \\
\hline 1 & 1 & 1 \\
\hline 0 & 1 & 0 \\
\hline
\end{tabular}$\quad$\begin{tabular}{|l|l|l|l|l|}
\hline 0 & 0 & 1 & 0 & 0 \\
\hline 0 & 1 & 1 & 1 & 0 \\
\hline 1 & 1 & 1 & 1 & 1 \\
\hline 0 & 1 & 1 & 1 & 0 \\
\hline 0 & 0 & 1 & 0 & 0 \\
\hline
\end{tabular}

\begin{tabular}{|c|c|c|c|c|c|c|}
\hline \multicolumn{7}{|c|}{$7 \times 7$} \\
\hline 0 & 0 & 0 & 1 & 0 & 0 & 0 \\
\hline 0 & 0 & 1 & 1 & 1 & 0 & 0 \\
\hline 0 & 1 & 1 & 1 & 1 & 1 & 0 \\
\hline 1 & 1 & 1 & 1 & 1 & 1 & 1 \\
\hline 0 & 1 & 1 & 1 & 1 & 1 & 0 \\
\hline 0 & 0 & 1 & 1 & 1 & 0 & 0 \\
\hline 0 & 0 & 0 & 1 & 0 & 0 & 0 \\
\hline
\end{tabular}

CA Markov is a combined CA, Markov Chain, Multi-Criteria Evaluation (MCE), Multi-Objective Land Allocation (MOLA) LULC prediction procedure that adds an element of spatial contiguity as well as knowledge of the likely spatial distribution of transitions to Markov chain analysis. CA Markov uses CA procedures in combination with Markov Chain analysis and MCE and MOLA routines. The transition probability matrix from a Markov Chain analysis of two prior LULC maps establishes the quantity of expected land use and land cover change from each existing category to each other category in the next time period. The basic LULC image [the later (second) land cover image of two time periods used in the Markov Chain analysis] is used as the starting point for change simulation. Suitability maps (here, evidence likelihood map) for each land cover establish the inherent suitability of each pixel for each land cover type. However, a contiguity filter down-weights the suitability of pixels far from existing areas of that class (as of that iteration), thus giving preference to contiguous suitable areas. The filter is integral to the action of CA component. Its purpose is to down-weight the suitability of pixels that are distant from existing instances of LULC type under consideration. The net effect is that to be a likely choice for LULC conversion, the pixel must be both inherently suitable and near to existing areas of that class. CA Markov automatically normalizes the filter kernel to force the values to sum to 1 (thus the values ultimately vary from 0 to 0.0076 ). This filter is passed over a Boolean image for each class from the current land cover image within each iteration. Following this, a value of 0.1111 is added to the filtered results to produce a set of weight images. These are multiplied by the original suitability maps to down-weight suitabilities distant from existing areas of each class. The results are then stretched back to a byte (0-255) range. The net effect is that down-weighted suitabilities never exceed a down-weighting in excess of $90 \%$ of their original value. This ensures that suitable areas can be found if none are available in proximate areas (Eastman et al., 2009).

\section{CALIBRATION OF THE CELLULAR AUTOMATA (CA) MARKOV MODEL}

CA Markov model have been used to monitor and predict the future land use land cover in a part of Brahmaputra River Basin, India, using land use land cover map derived from multitemporal satellite images (Figure 2). Land use land cover maps of the study area have been digitally classified from multi temporal satellite images i.e, Landsat MSS image of 1987, Landsat TM image of 1997 and IRS-P6 LISS III image of 2007 (Figure 2 and Table 1). Land use land cover maps derived (Figure 3, Table 2) from satellite images of Landsat MSS image of 1987 and Landsat TM image of 1997 were used to predict future land use land cover of 2007 using Cellular Automata Markov model. The validity of the Cellular Automata Markov process for projecting future land use and cover changes calculates using various Kappa Indices of Agreement (Kstandard) predicted (results) maps with the reference map, land use land cover map derived from IRS-P6 LISS III image of 2007 (Figure 3, Table 2). The validation shows Kstandard is $0.7928 .3 \times 3,5 \times 5$ and $7 \times 7$ CA contiguity filters are evaluated to predict LULC in 2007 using 1987 and 1997 LULC maps.

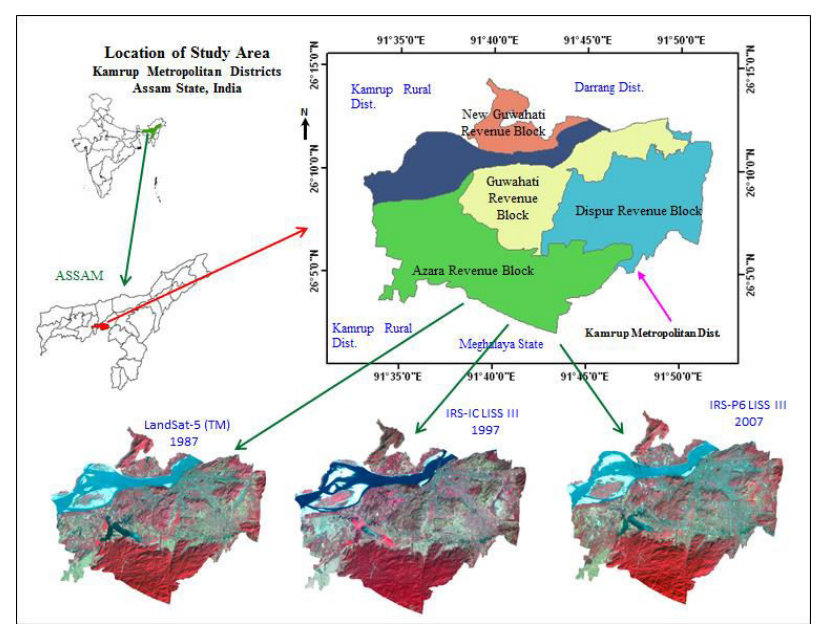

Figure 2. Location and satellite images of study area 


\begin{tabular}{|c|c|c|c|}
\hline $\begin{array}{c}\text { Satellite } \\
\& \\
\text { Sensor }\end{array}$ & $\begin{array}{c}\text { Data } \\
\text { Acquired }\end{array}$ & $\begin{array}{c}\text { Spatial } \\
\text { Resolution } \\
(\mathrm{m})\end{array}$ & Spectral Band \\
\hline $\begin{array}{l}\text { LANDSAT - } \\
5 \mathrm{TM}\end{array}$ & $\begin{array}{l}26-12- \\
1987\end{array}$ & $\begin{array}{l}30 \\
(120 \mathrm{~m}- \\
\text { thermal (B } \\
6))\end{array}$ & $\begin{array}{l}\text { B } 1 \text { (blue): } 0.45-0.52 \mu \mathrm{m} \\
\text { B } 2 \text { (green) : } 0.52-0.60 \mu \mathrm{m} \\
\text { B } 3 \text { (red): } 0.63-0.69 \mu \mathrm{m} \\
\text { B } 4 \text { (NIR): } 0.76-0.90 \mu \mathrm{m} \\
\text { B } 5 \text { (SWIR): } 1.55-1.75 \mu \mathrm{m} \\
\text { B } 6 \text { (thermal IR):10.4-12.5 } \\
\mu \mathrm{m} \\
\text { B } 7 \text { (Mid-Infrared) : } 2.08- \\
2.35 \mu \mathrm{m}\end{array}$ \\
\hline $\begin{array}{c}\text { IRS-1C } \\
\text { - LISS-III }\end{array}$ & $\begin{array}{l}05-03- \\
1997\end{array}$ & $\begin{array}{l}23.5 \\
(70 \mathrm{~m}-\mathrm{B} 5 \\
\text { (SWIR) ) }\end{array}$ & $\begin{array}{l}\text { B } 2 \text { (green) : } 0.52-0.59 \mu \mathrm{m} \\
\text { B } 3 \text { (red): } 0.62-0.68 \mu \mathrm{m} \\
\text { B } 4 \text { (NIR): } 0.77-0.86 \mu \mathrm{m} \\
\text { B } 5 \text { (SWIR): } 1.55-1.70 \mu \mathrm{m}\end{array}$ \\
\hline $\begin{array}{l}\text { IRS-P6 } \\
\text { (Resourcesat- } \\
\text { 1) - LISS-III }\end{array}$ & $\begin{array}{l}14-12- \\
2007\end{array}$ & 23.5 & $\begin{array}{l}\text { B } 2 \text { (green) : } 0.52-0.59 \mu \mathrm{m} \\
\text { B } 3 \text { (red): } 0.62-0.68 \mu \mathrm{m} \\
\text { B } 4 \text { (NIR): } 0.77-0.86 \mu \mathrm{m} \\
\text { B } 5 \text { (SWIR): } 1.55-1.70 \mu \mathrm{m}\end{array}$ \\
\hline
\end{tabular}

Table 1: Details of satellite data used in the study

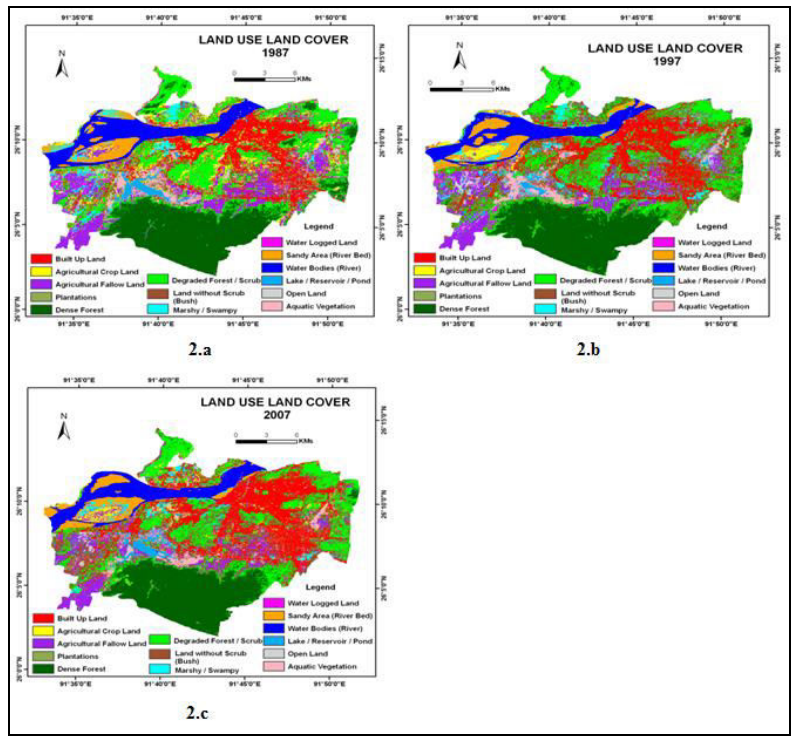

Figure 3. Classified Land Use Land Cover Map of 1987, 1997 and 2007

\begin{tabular}{|c|c|c|c|c|}
\hline Sl. & Class Name & \multicolumn{3}{|c|}{$\operatorname{Area}\left(\mathbf{k m}^{2}\right)$} \\
\hline & & 1987 & 1997 & 2007 \\
\hline 1. & Built Up Land & 60.54 & 102.4 & 141.35 \\
\hline 2. & Agricultural CropLand & 25.91 & 5.99 & 7.17 \\
\hline 3. & Agricultural FallowLand & 48.27 & 34.08 & 25.12 \\
\hline 4. & Plantations & 1.38 & 3.68 & 3.35 \\
\hline 5. & Dense Forest & 86.26 & 80.56 & 74.84 \\
\hline 6. & Degraded Forest & 83.48 & 76.95 & 60.31 \\
\hline 7. & $\begin{array}{l}\text { Land with or without } \\
\text { Scrub }\end{array}$ & 9.48 & 24.82 & 23.78 \\
\hline 8. & Marshy / Swampy & 13.42 & 10.26 & 6.82 \\
\hline 9. & Water Logged Area & 3.57 & 1.86 & 1.52 \\
\hline 10. & Sandy Area (River Bed) & 14.83 & 16.08 & 15.92 \\
\hline 11. & River / Stream & 37.27 & 32.51 & 33.42 \\
\hline 12. & Lake/Reservoir/Pond/Tank & 7.99 & 6.05 & 6.59 \\
\hline 13. & OpenLand & 13.8 & 7.28 & 6.97 \\
\hline 14. & Aquatic Vegetation & 7.78 & 11.46 & 6.82 \\
\hline & Total & 413.98 & 413.98 & 413.98 \\
\hline
\end{tabular}

Table 2: Area statistics of LULC (land use land cover)
To predict land use and land cover change for next 10 year using known LULC of 1987 and 1997, probability statistics for land use and land cover change for 2007 has been generated through cross tabulation of two LULC maps. Thus, CA Markov model combines both the concepts of Markov chain procedure and CA filters, after getting Markov transition probability, CA Markov used the transition probability matrix (Table 3) and probability images (here, suitability / evidence likelihood map) (Figure 4) to predict the LULC over a 10 years period i.e., 2007. The total numbers of iterations are based on the number of time steps, for 10 years model will choose to complete run in 10 iterations. With each pass, LULC suitability image is reweighted as a result of the contiguity filter on each existing LULC. Once re-weighted the revised suitability maps are the run through MOLA (Multi Objective Land Allocation), to allocate $1 / 10$ of the required land in first run and 2/10 in second run and so on until the full allocation of land for each LULC category is obtained.

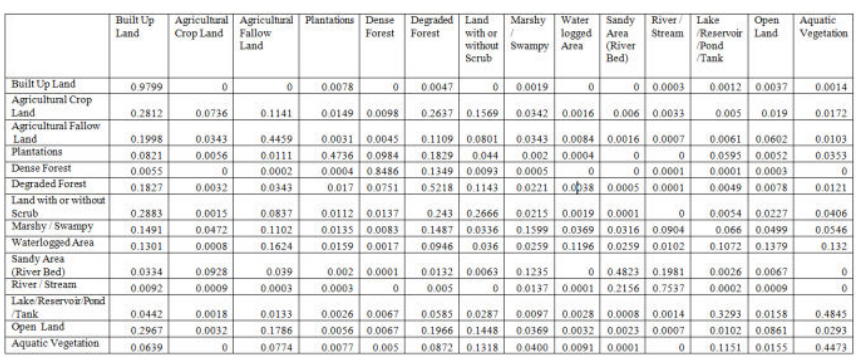

Table 3. Transition probability matrix of 1987 and 1997 LULC

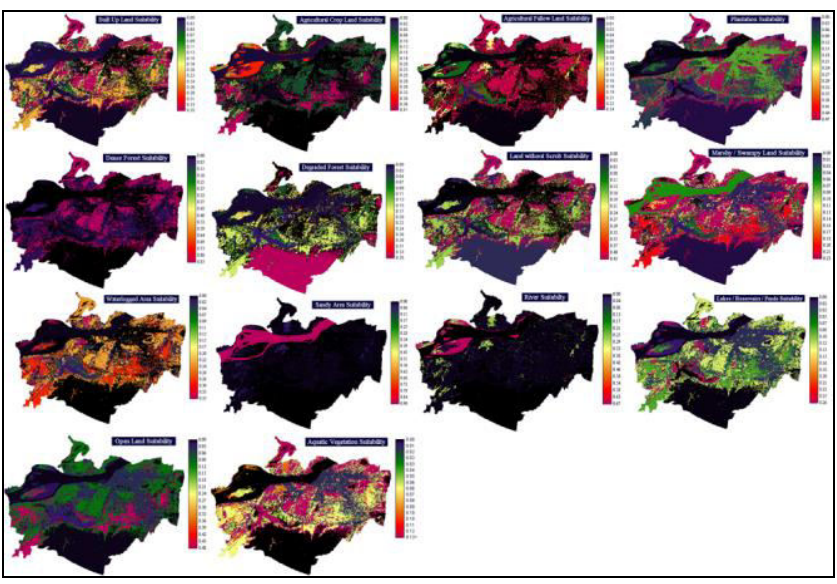

Figure 4. Suitability (evidence likelihood) map used to predict future LULC

The transition probability matrix has been determined how much land is allocated to each LULC category over 10 year period. Within each iteration, every LULC class typically loses some of its land to one or more other categories (and at the same time it may also gain land from others). Thus within the consideration of each host within each iteration, claimant classes select land from the host based on the suitability map for the claimant class. Since there will commonly be competition for specific land parcels, this process of land allocation is undertaken using a MOLA. The CA component arises in part from the iterative process of land allocation, and in part from a filtering stage with each iteration that reduces the suitability's of land away from exiting areas of that type. By filtering a Boolean mask of the class being considered, the mean filter yields a 
value of 1 when it is entirely within the existing class and when it is entirely outside. However, when it crosses the boundary, it will yield values that quickly transition from 1 to 0 . This result is then multiplied by the suitability image to that class. Note that class is defined at each step to incorporate new area of growth, and $3 \times 3,5 \times 5$ and $7 \times 7$ CA contiguity filters are evaluated to predict LULC in 2007 using 1987 and 1997 LULC maps. CA Markov is computationally intensive - a typical run involved several thousand GIS operations. The net results of this iterative process are that land use and land cover change develops as a high suitability proximate to existing areas.

\section{SIMULATED (PREDICTED) RESULTS AND EFFECT OF CONTIGUITY FILTERS ON SIMULATED (PREDICTED) RESULTS}

\subsection{Predicting Quantity}

Fourteen LULC classes are used to compute Markov transition probabilities and to predict the future LULC. The quantitative results are shows in Table 4 and Figure 5. Analysing from the quantitative figures of simulated-forecasted, predicted 14 scenarios are slightly different from LULC derived from LISS III image of 2007. Relative difference in predicted LULC of 2007 and LULC derived from LISS III image of 2007 ranges between (+) $15.88 \mathrm{~km}^{2}$ and (-) $16.26 \mathrm{~km}^{2}$ only. This difference is small, $\pm 1.34 \mathrm{~km}^{2}$ per year in a study area of $413.98 \mathrm{~km}^{2}$. Correlation between predicted two LULC classes are strong, where $r=0.983$ and $R^{2}=0.967$ (Figure 6). It is established that predicted LULC of 2007 and LULC derived from LISS III Image of 2007 are strongly correlated; they are slightly different to each-other.

\begin{tabular}{|c|c|c|c|c|c|}
\hline \multirow[b]{3}{*}{ LULC Class } & \multicolumn{5}{|c|}{ Area (in Km²) } \\
\hline & \multicolumn{5}{|c|}{ Predicted LULC 2007 (Using $1987 \& 1997$ LULC Image) } \\
\hline & $\begin{array}{c}\mathbf{3 x 3 \mathrm { CA }} \\
\text { Contiguity } \\
\text { Filter }\end{array}$ & $\begin{array}{c}5 \times 5 \mathrm{CA} \\
\text { Contiguity } \\
\text { Filter }\end{array}$ & $\begin{array}{c}\mathbf{7 x} 7 \mathrm{CA} \\
\text { Contiguity } \\
\text { Filter }\end{array}$ & $\begin{array}{c}\text { LULC 2007 } \\
\text { (Derived } \\
\text { from LISS } \\
\text { III Image of } \\
\text { 2007) }\end{array}$ & Differences \\
\hline Built Up Land & 125.09 & 125.09 & 125.09 & 141.35 & -16.26 \\
\hline Agricultural Crop Land & 4.32 & 4.32 & 4.32 & 7.17 & -2.85 \\
\hline Agricultural Fallow Land & 23.62 & 23.62 & 23.62 & 25.12 & -1.50 \\
\hline Plantation & 10.57 & 10.57 & 10.57 & 3.35 & +7.22 \\
\hline Dense Forest & 66.26 & 66.26 & 66.26 & 74.84 & -8.58 \\
\hline Degraded Forest & 76.19 & 76.19 & 76.19 & 60.31 & +15.88 \\
\hline Land with or without Scrub & 24.95 & 24.95 & 24.95 & 23.78 & +1.17 \\
\hline Marshy/Swampy & 10.91 & 10.91 & 10.91 & 6.82 & +4.09 \\
\hline Waterlogged & 1.46 & 1.46 & 1.46 & 1.52 & -0.06 \\
\hline Sandy Area & 17.39 & 17.39 & 17.39 & 15.92 & +1.47 \\
\hline River & 25.72 & 25.72 & 25.72 & 33.42 & -7.70 \\
\hline Lakes/Reservoirs/Ponds & 6.31 & 6.31 & 6.31 & 6.59 & -0.28 \\
\hline Open Land & 8.67 & 8.67 & 8.67 & 6.97 & +1.70 \\
\hline Aquatic Vegetation & 12.52 & 12.52 & 12.52 & 6.82 & +5.70 \\
\hline Total & 413.98 & 413.98 & 413.98 & 413.98 & \\
\hline
\end{tabular}

Table 4. Area statistics of predicted LULC of 2007 using 1987 \& 1997 LULC image and LULC derived from LISS III image of 2007

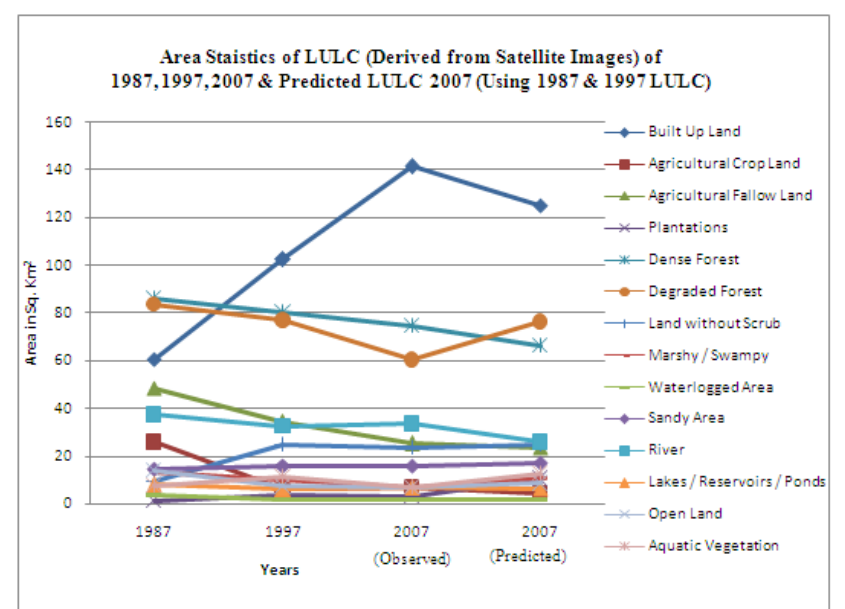

Figure 5. Area statistics of predicted LULC of 2007 using 1987 \& 1997 LULC image and LULC derived from LISS III image of 2007

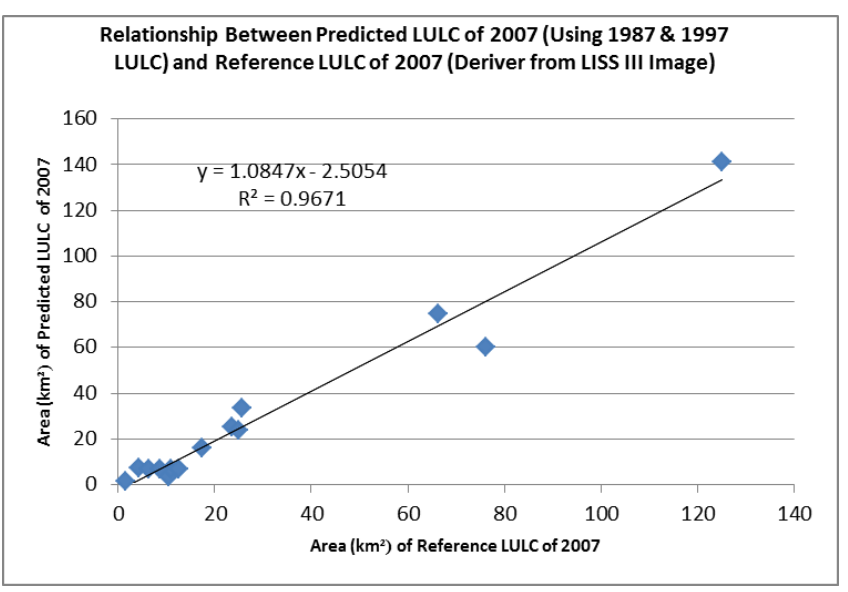

Figure 6. Relationship between predicted LULC of 2007 (using 1987 \& 1997 LULC image) and LULC derived from LISS III image of 2007

\subsection{Predicting Locations}

The predicted results of LULC, (using 1987 and 1997 LULC maps) by using $3 \times 3,5 \times 5$ and $7 \times 7$ CA contiguity filters in CA Markov model are shows in Figure 7, Figure 8 and Figure 9, respectively. When we look at the quantity of predicted LULC of 2007 area statistics derived by using $3 \times 3,5 \times 5$ and $7 \times 7$ CA contiguity filters, the predicted area statistics are the same. But when we look the area statistics of LULC derived from LISS III images of 2007 and predicted LULC of predicted LULC derived by using $3 \times 3,5 \times 5$ and $7 \times 7$ CA contiguity filter, these are slightly different as mentioned in previous paragraph. The spatial difference between predicted LULC of 2007 and LULC derived from LISS III images of 2007 is evaluated and they are found to be slightly different. Regression analysis of three pairs of images (predicted LULC of 2007 using 3x3 filter and LULC derived from LISS III images of 2007; predicted LULC of 2007 using $5 \times 5$ filter and LULC derived from LISS III images of 2007; predicted LULC of 2007 using $7 \times 7$ filter and LULC derived from LISS III images of 2007) established the spatial relationship amongst them. The linear equations derived from the regression analysis give us an idea about how much are these spatially related. Correlation coefficient between predicted 
LULC classes using 3x3 CA filters and LULC derived from LISS III image of 2007 is $\mathrm{r}=0.7906$ (Figure 10) where Correlation between predicted LULC classes using $5 \times 5$ CA filters and LULC derived from LISS III Image of 2007 is $r=$ 0.7929 (Figure 11) and correlation coefficient (r) between predicted LULC classes using 7x7 CA filters and LULC derived from LISS III image of 2007 is $r=0.7927$ (Figure 12). Therefore, the $5 \times 5$ contiguity filters (correlation coefficient $(r)$ when using $5 \times 5$ filters is highest among $3 \times 3,5 \times 5$, and $7 \times 7$ filters) produce most geographically / spatially distributed effective results, although the differences between them are very small.

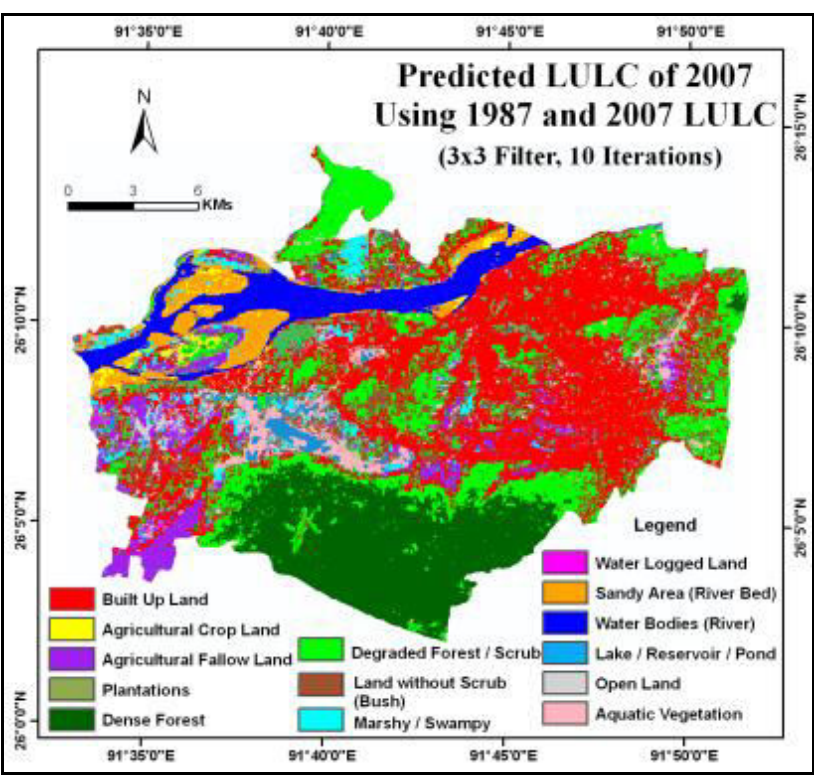

Figure 7. Predicted LULC of 2007 using 1987 \& 1997 LULC image ( $3 \times 3$ contiguity filter, 10 iterations)

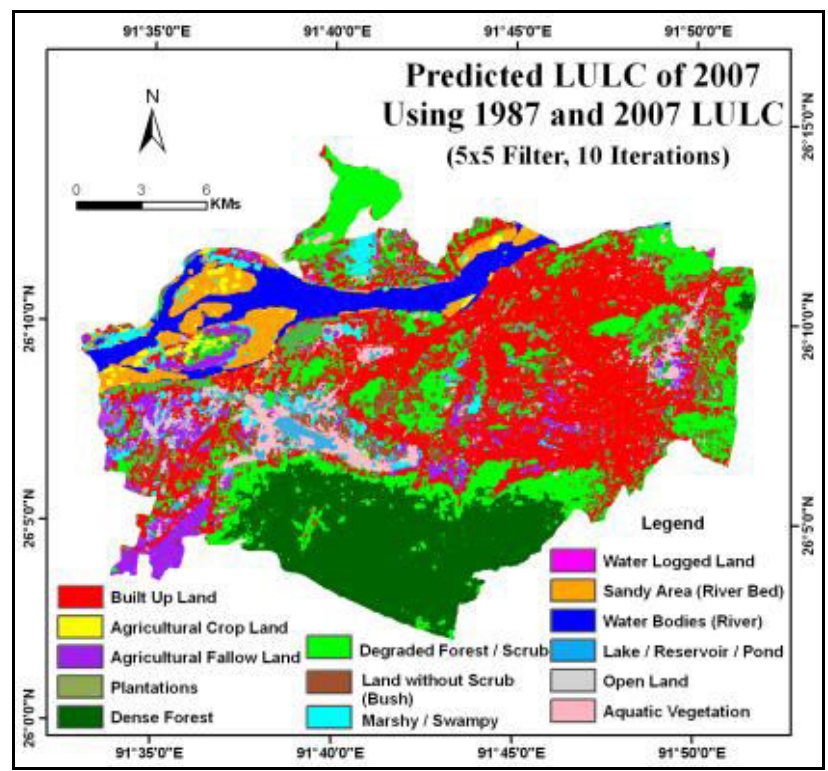

Figure 8. Predicted LULC of 2007 using 1987 \& 1997 LULC image ( $5 \times 5$ contiguity filter, 10 iterations)

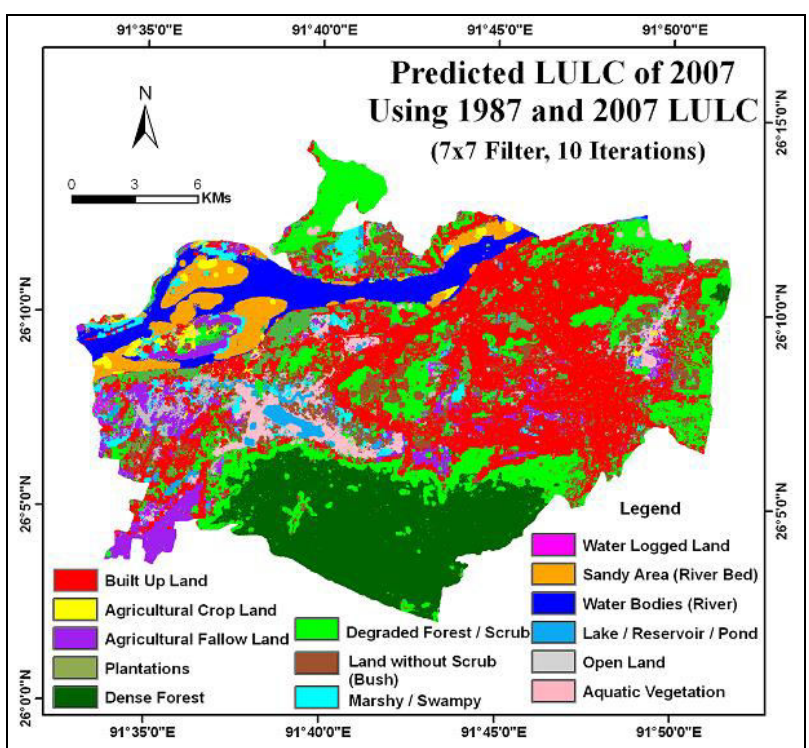

Figure 9. Predicted LULC of 2007 using 1987 \& 1997 LULC image ( $7 \times 7$ contiguity filter, 10 iterations)

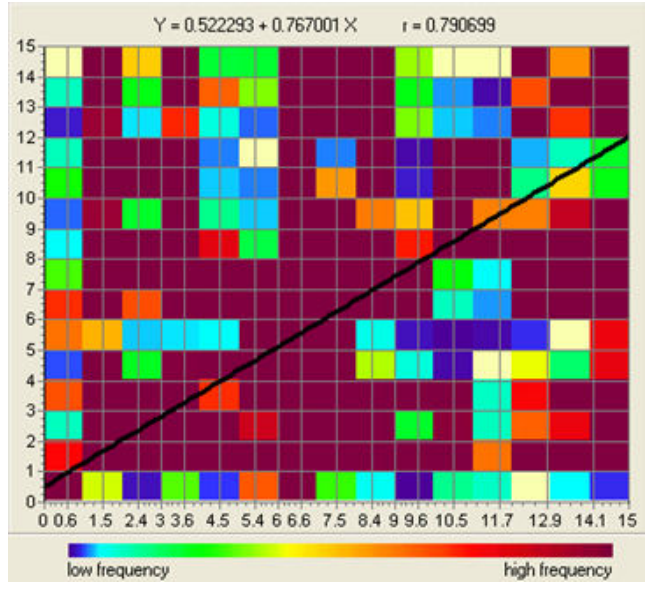

Figure 10. Spatial relationship between predicted LULC of 2007 (using $3 \times 3$ contiguity filter) and LULC derived from LISS III image of 2007 (references image)

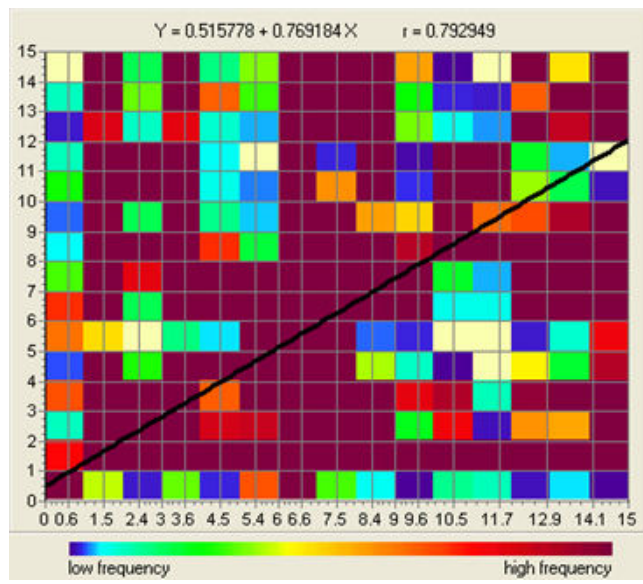

Figure 11. Spatial relationship between predicted LULC of 2007 (using 5x5 contiguity filter) and LULC derived from LISS III image of 2007 (references image) 


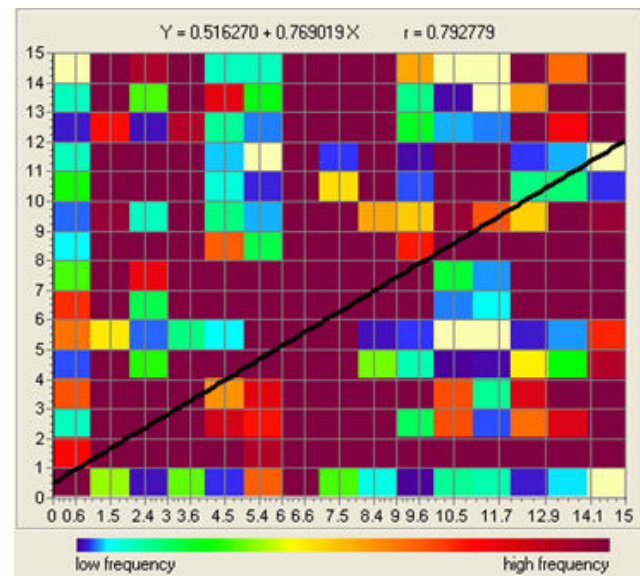

Figure 12. Spatial relationship between predicted LULC of 2007 (using 7x7 contiguity filter) and LULC derived from LISS III image of 2007 (references image)

\subsection{Validation of Simulated / Predicted Results - Kappa for Quantity and Location}

Pontius et al. (2002) suggested how to use measurements of both - the quantity and the location of land categories for prediction over several decades at multiple resolutions and also suggested the use Kappa statistics for testing the accuracy in terms of location (Kappa for location) and quantity of correct cells (Kappa for quantity). This provides a method to measure agreement between two categorical images, a "comparison" map here the predicted LULC of 2007 and a "reference" map i.e., LULC map derived from IRS-P6 LISS III image of 2007. The comparison map is the result of CA Markov model simulation results, whose validity is being assessed against a reference map that depicts reality. The validation offers one comprehensive statistical analysis for $3 \times 3,5 \times 5,7 \times 7$ contiguity filters that answered that the quantity is same for $3 \times 3,5 \times 5$ and $7 \times 7$ filters (Table 5, Table 6, Table 7, respectively) but spatially (Kappa Index of Agreement - Kappa for location) slightly different (Table 8). $\mathrm{K}_{\text {no }}$ are $0.8290,0.8347,0.8226$ for $3 \times 3,5 \times 5$, $7 \times 7$ contiguity filters, respectively. $\mathrm{K}_{\text {location }}$ and $\mathrm{K}_{\text {locationstrata }}$ are 0.8513, $0.8591, \quad 0.8427$ for $3 \times 3, \quad 5 \times 5, \quad 7 \times 7$ contiguity filters, respectively. The $\mathrm{K}_{\text {standard }}$ for $5 \times 5$ filters is 0.7928 whereas $K_{\text {standard }}$ for $3 \times 3$ filters is 0.7857 and for $7 \times 7$ filters is 0.7777 . The results also indicating one more important facts that CA Markov model's ability to specify grid cell level location of future change is nearly perfect (here $\mathrm{K}_{\text {location }}$ value is 0.859 , where $\mathrm{K}_{\text {location }}$ value of 1 is perfect).

\begin{tabular}{|c|c|c|c|c|}
\hline \multirow[t]{2}{*}{ Sl. No. } & \multirow[t]{2}{*}{ Information of Location } & \multicolumn{3}{|c|}{ Information of Quality } \\
\hline & & No[n] & Medium[m] & Perfect[p] \\
\hline 1. & Perfect $[\mathrm{P}(\mathrm{x})]$ & $\mathrm{P}(\mathrm{n})=0.4592$ & $\mathrm{P}(\mathrm{m})=0.9478$ & $\mathrm{P}(\mathrm{p})=1.0000$ \\
\hline 2. & PerfectStratum $[\mathrm{K}(\mathrm{x})]$ & $\mathrm{K}(\mathrm{n})=0.4592$ & $\mathrm{~K}(\mathrm{~m})=0.9478$ & $\mathrm{~K}(\mathrm{p})=1.0000$ \\
\hline 3. & MediumGrid[M(x)] & $\mathrm{M}(\mathrm{n})=0.4397$ & $\mathrm{M}(\mathrm{m})=0.8599$ & $\mathrm{M}(\mathrm{p})=0.8890$ \\
\hline 4. & MediumStratum $[\mathrm{H}(\mathrm{x})]$ & $\mathrm{H}(\mathrm{n})=0.1522$ & $\mathrm{H}(\mathrm{m})=0.3235$ & $\mathrm{H}(\mathrm{p})=0.3261$ \\
\hline 5. & $\mathrm{No}[\mathrm{N}(\mathrm{x})]$ & $\mathrm{N}(\mathrm{n})=0.1522$ & $\mathrm{~N}(\mathrm{~m})=0.3235$ & $\mathrm{~N}(\mathrm{p})=0.3261$ \\
\hline
\end{tabular}

\begin{tabular}{|c|c|}
\hline Agreement Chance & 0.1522 \\
\hline Agreement Quantity & 0.1713 \\
\hline Agreement Strata & 0.0000 \\
\hline Agreement Grid cell & 0.5363 \\
\hline Disagree Grid cell & 0.0880 \\
\hline Disagree Strata & 0.0000 \\
\hline Disagree Quantity & 0.0522 \\
\hline
\end{tabular}

Table 5. Agreement/disagreement according to ability to specify accurately quantity and location to predict 2007 LULC using $3 \times 3$ contiguity filter

\begin{tabular}{|l|l|c|c|c|}
\hline Sl. No. & Information of Location & \multicolumn{3}{|c|}{ Information of Quality } \\
\cline { 3 - 5 } & & No[n] & Medium[m] & Perfect[p] \\
\hline 1. & Perfect[$[\mathrm{P}(\mathrm{x})]$ & $\mathrm{P}(\mathrm{n})=0.4592$ & $\mathrm{P}(\mathrm{m})=0.9478$ & $\mathrm{P}(\mathrm{p})=1.0000$ \\
\hline 2. & PerfectStratum $[\mathrm{K}(\mathrm{x})]$ & $\mathrm{K}(\mathrm{n})=0.4592$ & $\mathrm{~K}(\mathrm{~m})=0.9478$ & $\mathrm{~K}(\mathrm{p})=1.0000$ \\
\hline 3. & MediumGrid[M(x)] & $\mathrm{M}(\mathrm{n})=0.4398$ & $\mathrm{M}(\mathrm{m})=0.8550$ & $\mathrm{M}(\mathrm{p})=0.8856$ \\
\hline 4. & MediumStratum $[\mathrm{H}(\mathrm{x})]$ & $\mathrm{H}(\mathrm{n})=0.1522$ & $\mathrm{H}(\mathrm{m})=0.3235$ & $\mathrm{H}(\mathrm{p})=0.3261$ \\
\hline 5. & No[N(x)] & $\mathrm{N}(\mathrm{n})=0.1522$ & $\mathrm{~N}(\mathrm{~m})=0.3235$ & $\mathrm{~N}(\mathrm{p})=0.3261$ \\
\hline
\end{tabular}

\begin{tabular}{|c|c|}
\hline Agreement Chance & 0.1522 \\
\hline Agreement Quantity & 0.1713 \\
\hline Agreement Strata & 0.0000 \\
\hline Agreement Grid cell & 0.5315 \\
\hline Disagree Grid cell & 0.0928 \\
\hline Disagree Strata & 0.0000 \\
\hline Disagree Quantity & 0.0522 \\
\hline
\end{tabular}

Table 6. Agreement/disagreement according to ability to specify accurately quantity and location to predict 2007 LULC using $5 \times 5$ contiguity filter

\begin{tabular}{|l|l|c|c|c|}
\hline Sl. No. & \multirow{2}{*}{ Information of Location } & \multicolumn{3}{|c|}{ Information of Quality } \\
\cline { 3 - 5 } & & No[n] & Medium[m] & Perfect[p] \\
\hline 1. & Perfect[$[\mathrm{P}(\mathrm{x})]$ & $\mathrm{P}(\mathrm{n})=0.4592$ & $\mathrm{P}(\mathrm{m})=0.9478$ & $\mathrm{P}(\mathrm{p})=1.0000$ \\
\hline 2. & PerfectStratum $[\mathrm{K}(\mathrm{x})]$ & $\mathrm{K}(\mathrm{n})=0.4592$ & $\mathrm{~K}(\mathrm{~m})=0.9478$ & $\mathrm{~K}(\mathrm{p})=1.0000$ \\
\hline 3. & MediumGrid[M(x)] & $\mathrm{M}(\mathrm{n})=0.4391$ & $\mathrm{M}(\mathrm{m})=0.8496$ & $\mathrm{M}(\mathrm{p})=0.8820$ \\
\hline 4. & MediumStratum[H(x)] & $\mathrm{H}(\mathrm{n})=0.1522$ & $\mathrm{H}(\mathrm{m})=0.3235$ & $\mathrm{H}(\mathrm{p})=0.3261$ \\
\hline 5. & No[ $[\mathrm{N}(\mathrm{x})]$ & $\mathrm{N}(\mathrm{n})=0.1522$ & $\mathrm{~N}(\mathrm{~m})=0.3235$ & $\mathrm{~N}(\mathrm{p})=0.3261$ \\
\hline
\end{tabular}

\begin{tabular}{|c|c|}
\hline Agreement Chance & 0.1522 \\
\hline Agreement Quantity & 0.1713 \\
\hline Agreement Strata & 0.0000 \\
\hline Agreement Grid cell & 0.5261 \\
\hline Disagree Grid cell & 0.0982 \\
\hline Disagree Strata & 0.0000 \\
\hline Disagree Quantity & 0.0522 \\
\hline
\end{tabular}

Table 7. Agreement/disagreement according to ability to specify accurately quantity and location to predict 2007 LULC using $7 \times 7$ contiguity filter

\begin{tabular}{|c|c|c|c|}
\hline & $\begin{array}{c}3 \times 3 \\
\text { Contiguity } \\
\text { Filter }\end{array}$ & $\begin{array}{c}5 \times 5 \\
\text { Contiguity } \\
\text { Filter }\end{array}$ & $\begin{array}{c}7 \times 7 \\
\text { Contiguity } \\
\text { Filter }\end{array}$ \\
\hline $\mathrm{K}_{\mathrm{no}}$ & 0.8290 & 0.8347 & 0.8226 \\
\hline $\mathrm{K}_{\text {location }}$ & 0.8513 & 0.8591 & 0.8427 \\
\hline $\mathrm{K}_{\text {locationstrata }}$ & 0.8513 & 0.8591 & 0.8427 \\
\hline $\mathrm{K}_{\text {standard }}$ & 0.7857 & 0.7928 & 0.7777 \\
\hline
\end{tabular}

Table 8. Kappa Index of Agreement to ability to specify accurately quantity and location to predict 2007 LULC using $3 \times 3,5 \times 5,7 \times 7$ contiguity filter

\section{CONCLUSIONS}

CA Markov LULCC simulation and forecast model is a meaningful exploration by combining of the process of CA and Markov chain analysis, which takes the complexity of combination CA, Markov chain, multi-criteria evaluation (MCE), and multi-objective land allocation (MOLA) into land use and land cover change account. The spatial simulation accuracy of CA Markov model is also good, not only quantitatively as well as spatially. Quantitatively it's near reality. Spatially also, it's also near reality. After getting suitable parameters (drivers variables), we can get the results that is close to the reality. The results of simulation are not just a kind of probability, as well as spatial expression has great 
meanings for revealing LULCC dynamic mechanism, exploring the simulate and forecast the spatio-temporal pattern and distribution of LULCC in the future in different scenarios. Regression analysis have been carried out for both predicted quantity as well as prediction location to established the cellular automata (CA) contiguity filters impacts on predictions results. Correlation established that predicted LULC of 2007 and LULC derived from LISS III Image of 2007 are strongly correlated and they are slightly different to each-other but the quantitative prediction results are same for when $3 \times 3,5 \times 5$ and $7 \times 7$ CA contiguity filters are evaluated to predict land use land cover. When we look at the quantity of predicted land use land cover of 2007 area statistics derived by using $3 \times 3,5 \times 5$ and $7 \times 7$ CA contiguity filters, the predicted area statistics are the same. Other hands, the spatial difference between predicted LULC of 2007 and LULC derived from LISS III images of 2007 is evaluated and they are found to be slightly different. Correlation coefficient ( $\mathrm{r}$ ) between predicted LULC classes and LULC derived from LISS III image of 2007 using 3x3, 5x5, 7x7 are $0.7906,0.7929,0.7927$, respectively. Therefore, the correlation coefficient (r) for $5 \times 5$ contiguity filters is highest among $3 \times 3$, $5 \times 5$, and $7 \times 7$ filters and established/produced most geographically / spatially distributed effective results, although the differences between them are very small. Kappa Index of Agreement $\left(\mathrm{K}_{\text {location }}\right.$ and $\left.\mathrm{K}_{\text {locationstrata }}\right)$ are $0.8513,0.8591,0.8427$ for $3 \times 3,5 \times 5,7 \times 7$ contiguity filters, respectively. Kappa Index of Agreement $\left(\mathrm{K}_{\text {location }}\right.$ and $\left.\mathrm{K}_{\text {locationstrata }}\right)$ also showing highest for $5 \times 5$ contiguity filters among $3 \times 3,5 \times 5$, and $7 \times 7$ filters.

\section{ACKNOWLEDGEMENTS}

The authors are thankful to EU for financial support received to carry out this study.

\section{REFERENCES}

Baker, W. L., 1989, A review of models of landscape change. Landscape Ecology, 2, pp. 111133.

Clarke K. C., 1997, Land transition modeling with deltatrons. In Proceedings of the Land Use Modeling Workshop, June 1997, Santa Barbara, California, Available online at: http://www.ncgia.ucsb.edu (accessed 1 June 2007).

Eastman JR. 2009. IDRISI users guide. Massachusetts: Clark University.

Mertens, B. And Lambin E. F., 1997, Spatial modeling of deforestation in Southern Cameroon. Applied Geogr., 17, pp. 143-162.

Mondal M. S., Sharma N., Kappas M., Garg P. K., 2012, Modeling of spatiotemporal dynamics of LULC - a review and assessment. Journal of Geomatics, 6(2), pp. 93-103.

Pontius Jr, R. G., 2002, Statistical methods to partition effects of quantity and location during comparison of categorical maps at multiple resolutions. Photogrammetric Engineering \& Remote Sensing, 68(10): 1041-1049.

Pontius Jr., R. G., Huffaker D. and Denman K., 2004, Useful techniques of validation for spatially explicit land-change models. Ecological Modelling, 179(4), pp. 445-461.
Turner II, B. L., Skole D., Sanderson S., Fischer G., Fresco L. and Leemans R., 1995, Land-Use and Land-Cover Change, Science/Research Plan, IHDP Report No. 07, IGBP report No. 35.

Veldkamp, A., and Fresco I. O., 1996, CLUE: A conceptual model to study the conversion of land use and its effects, Ecological Modelling, 85(2-3), pp. 253-270.

Wu F. and Webster C. J., 1998, Simulation of land development through the integration of $\mathrm{CA}$ and multi-criteria evaluation, Environment and Planning B, 25, pp. 103-126. 